and, therefore, have had their day. Rubber tubes, augmented, if necessary, with gauze, do all that is required. Should the gauze stick it is easily loosened with solution of peroxide of hydrogen and that drug is also most excellent for the cleansing of the abscess cavity should it again become foul. I have recently seen gangrene of the abdominal wall, following upon the opening of an appendicular abscess, at once arrested by its application in a 5 per cent. solution.

As a rule the patient recovers with wonderful rapidity after the evacuation of the abscess and the remoral of the appendix. The three chief complications to be feared are shock, vomiting, and flatulent distension. But as all of these, especially the latter, become better understood, so do their dangers diminish. When flatulent distension is present at the time of operation the question of enterotomy and evacuation of gas and liquid fæces has to be entertained. My own experience of incising and emptying the intestines for distension due to peritonitis leads me to consider the expedient a safe one. I have not yet seen the apertures leak into the peritoneal cavity. Experience may decide that in some cases the incision into the intestine ought to be sewn to the abdominal wall to act as a safety vent for a few days. Such openings close provided there is no occlusion of the intestine beyond. The flatulent distension which follows the operation may be met by the skilful use of enemas and by calomel or even croton oil. I have not yet tried the introduction of aperients into the cæcum through the stump of the appendix or through a puncture made for the purpose. It seems to me better to avoid anything which might injure the cecum and I confess a certain antipathy to the introduction of syringes and purgative solutions into the field of operation.

Such, Sir, is a brief summary of some of the points in the surgery of acute appendicitis which, in my opinion, are in need of discussion. Many more remain, but the disease is protean in its manifestations, and, after all, our time is brief.

\section{THE CLINICAL HISTORY AND SYMP'TOMS OF 120 CASES OF EXOPHTHALMIC GOITRE. ${ }^{1}$}

BY GEORGE R. MURRAY, M.A., M.D. CaNTAB., F.R.C.P. LOND.,

HEATH PROFESSOR OF COMPARATIVE PÁTHOLOGY IN DURHAM UNIVERSITY; PHYSICLAN TO THE ROYAL INEIRMARY, NEWCASTLE; PRESIDENT OF THE NORTHUMBERLAND AND DURHAM MEDICAL SOCIETY.

WHEN Sir Thomas Barlow, the late secretary of the Royal Medical and Chirurgical Society, honoured me by an invitation to read a paper it occurred to me that a short review of the main features in the clinical history and symptoms of the cases of exophthalmic goitre which I have seen during the last eleven and a half years while in practice in the North of England might be of interest to the Fellows of this Society. During this period I have taken notes on 120 cases and these form the basis of this communication. I regret that in many cases the records are very brief and omit many details ; still the main features have generally been noted and can be utilised in comparing the frequency of certain symptoms. Owing to the circumstances of consulting and hospital practice I have not been able in the majority of the cases to make continuous observations like those recorded by Mr. A. Maude of Westerham, as many of the patients have only been seen once or on a few occasions at longer or shorter intervals.

We may first consider the circumstances of the patients which may have any bearing upon the conditions under Which the disease arises.

Sex. - Of the 120 cases 110 were women and 10 were men, showing an exact proportion of 11 to 1 . This emphasises the well-known fact that women are much more liable than men to suffer from Graves's disease. Of the 110 women 57 were married, one was a widow, and 42 were single. Of the 10 men two were married, one was a widower, and three were single. The social state of the remaining 10 women and four men was not recorded.

I A paper read at a meeting of the Royal Medical and Chirurgical society on Oct. 28th, 1902.
Locality.-In 86 cases the county in which the patient lived was noted. 41 lived in Northumberland, 37 in Durham, three in Yorkshire, and one each in Aberdeen, Buckingham, London, Rutland, and Stafford.

Age.- In considering the age of the cases I have taken the age at which the symptoms were first noticed and not when the patient was seen. This was ascertained in 97 cases. The onset in some cases was insidious, and so the age at which the disease actually commenced could be fixed only approximately. In those cases in which there was a history of goitre long antecedent to the other symptoms the age of onset taken was that at which other symptoms developed in addition to the goitre. The youngest patient was 15 years old and the oldest was 65 years of age at the time when the disease developed. For convenience the cases have been arranged in quinquennial periods from 15 to 50 years which gives the following results in tabular form :-

TABLE I.-Showing the Age at which the Symptoms developed.

\begin{tabular}{|c|c|c|c|c|c|}
\hline \multicolumn{3}{|c|}{ Age. } & Males. & Females. & Total. \\
\hline Between & 15 and 20 & years. & 2 & 14 & 16 \\
\hline$"$ & $20 \quad, \quad 25$ & , & 2 & 17 & 19 \\
\hline$"$ & $25 \quad, \quad 30$ & , & 0 & 16 & 16 \\
\hline , & $30 \quad, \quad 35$ & , & 4 & 14 & 18 \\
\hline , & $35 \quad, \quad 40$ & , & 0 & 4 & 4 \\
\hline$"$ & $40,, 45$ & , & 0 & 10 & 10 \\
\hline ", & $45 \quad, \quad 50$ & , & 1 & 7 & 8 \\
\hline$"$ & $50 \quad, \quad 55$ & : & 0 & 4 & 4 \\
\hline Aged & 58 years. & & 0 & 1 & 1 \\
\hline , & 65 & & 0 & 1 & 1 \\
\hline & - & & 9 & 88 & 97 \\
\hline
\end{tabular}

Thus, from 15 to 35 years nearly an equal number of cases started in each period of five years and in these 20 years preceding the age of 3569 cases developed, as compared with 26 which commenced in the 20 years following that age. If we take the whole period of 50 years from 15 to 65 we find that 69 , or five-sevenths of the cases, developed in the first 20 years, as compared with 28 , or two-sevenths, in the remaining 30 years. These figures show that the greatest liability to the disease exists from 15 to 35 years of age.

Heredity. - There was no history of exophthalmic goitre in either of the parents in any case. Two of the cases in the series were brother and sister. One female patient's sister had died from exophthalmic goitre. One patient came to see me with two of her sisters wbo are not included in the series, both of whom had had goitres as long as they could remember. One had also pigmentation of the skin and the pulse was 108 ; the other, who was Fregnant, had also a dark skin and the pulse was 100 . Another patient's sister had slight symptoms of goitre, tremors, and nervousness, but her pulse was 86 and so she is not included in this series. In one case a paternal aunt had exophthalmic goitre, lived for 20 years afterwards, and ultimately died from diabetes; in another a maternal aunt suffered from exophthalmic goitre. The father of one patient had a goitre, while her sister had goitre, rapid pulse, and tremors. Two of the male patients had each a sister with simple goitre.

Exciting cause. - In some of the cases certain circumstances appeared to have a definite relationship to the onset of the disease and may be considered as exciting causes. Sudden or prolonged grief and anxiety were the most important of these. Thus, in one case which I saw with Dr. W. Mearns of Gateshead, a sister who also had severe exophthalmic goitre was found dead in bed nine months before the symptoms developed in our patient. In one case the sudden death of a brother, in another the sudden and unexpected death of the father in the presence of the patient one year before the goitre appeared, and in another the sudden death of the mother who suffered from "fits," appeared to be connected with the development of the disease. As examples of prolonged anxiety may be mentioned one case in which the prolonged illness and death of the patient's fiancé from phthisis were considered to be the cause of the illness: in another case a wife had nursed her husband up to his death from phthisis and when I saw her 
was suffering from early phthisis as well as from exophthalmic goitre. In other cases overwork and mental anxiety had also played their part. Of acute illnesses, influenza in three cases and scarlet fever in one case had shortly preceded the onset of the symptoms. In one case sudden cessation of menstruation for seven months after a wetting during a menstrual period and in another hard work in front of a hot furnace causing profuse perspiration were supposed to be the exciting causes. In only two of the cases did an accident contribute to the development of the disease. In one of them a bundle of wet clothes fell from a height of some 20 feet on to the patient's head and the symptoms appeared a month afterwards. In the other case the patient fell off a plank into deep water and was nearly drowned; siz months afterwards the goitre appeared, 18 months later palpitation, and seven years after the accident she had wellmarked exophthalmic goitre. Her sister, who was with her, went into the water after her; eight years later she also developed goitre, followed by palpitation and tremors; as, however, her pulse was only 86 when I saw her she is not included in this series. In some of these cases it may be objected that the interval is too long and that it is merely a case of post hoc and not propter hoc. I have, however, thought it well to mention them, as the patients themselves attached considerable importance to the events just related.

Onset. - The onset was usually gradual, though in some cases it was more rapid. In one interesting case which I saw with Mr. V. Howard of Buckingham the disease started suddenly one night with violent palpitation and headache; by the end of a fortnight there were well-marked enlargement of the thyroid gland and exophthalmos in additicn to the rapid pulse. In another case palpitation and dyspnoea came on suddenly and a week later there were enlargement of the right lobe of the thyroid gland and nerrousness. The first symptom most commonly noticed was the goitre. Thus, taking 87 cases in which either one symptom or two symptoms simultaneously appeared before the others, an enlargement of the thyroid gland was the first sign of the disease in 43. This number, however, includes those cases in which a simple goitre preceded the other symptoms by a distinct interval and which will be referred to again. In 19 cases palpitation was complained of before the other symptoms were noticed. In four cases only was the exophthalmos the first symptom, and in the same number either nervousness or tremor was first noticed. In one case rapid respiration was the first symptom which developed. Palpitation and nervousness or other nervous symptom developed at the same time in seven cases, exokhthalmos and palpitation in four, goitre and palpitation in three, exophthalmos and goitre in one, and diarrhoea and excessive perspiration in one.

\section{SYMPTOMS,}

Thyroid gland.-In considering the symptoms present in these cases I will take the thyroid gland first. This was enlarged in 112 cases at the time the patient was examined. In five cases there was a history of previous enlargement which had disappeared before the case was seen. In only three cases was there entire absence of enlargement both before and at the time of the examination. Thus goitre was present at some period of the attack in 117 cases, and entirely absent in only three of the 120 cases. These figures emphasise the fact that the enlargement of the thyroid gland is a very frequent symptom, which was only absent in $2 \frac{1}{2}$ per cent. of my cases. It not infrequently occurs that a patient who has had for some time a simple goitre with only local signs develops other symptoms of exophthalmic goitre at a later stage. In at least 14 cases there had evidently been a simple goitre for some years before other symptoms were observed. In one case the goitre had been present 34 years and in another 32 before the onset of other signs of Graves's disease, and in other cases for varying periods of approximately $25,18,12,10,8,6$, and 3 years. Why this should occur in some cases of simple goitre and after such varying periods of duration is difficult to explain. Thus in June, 1899, I saw a brother, aged 19 years, and a sister, aged 16 years; the former had a soft parenchymatous goitre of nine months' duration and the circumference of the neck was 17 inches ; the latter had a similar goitre of six months' duration, the circumference of the neck being 14 inches. Only local symptoms were present in both cases, the brother's pulse being 72 and the sister's $88 . \quad$ I saw the brother again in November, 1901, when he had well-marked Graves's disease with a loss of some two and a half or three stones in weight, a pulse of 106, restlessness, tremors, and slight exophthalmos. The circumference of the neck was 15 inches, though this diminution was largely due to the marked emaciation. I could find no explanation of the development of the Graves's disease in the brother while the sister escaped. The practical lesson to be learned from this not uncommon sequence of events is that in all cases of simple goitre in which surgical treatment is contemplated it is important to make sure that no symptoms of Graves's disease are present, such as tachycardia, tremors, \&c. All cases of Graves's disease bear operations badly, and in the presence of such symptoms any operative treatnent for the relief of goitre is more dangerous, and is therefore, if possible, to be avoided except in cases where some local condition, such as compression of the trachea, is so marked as to render an operation for the relief of the dyspnoea imperative.

The degree of enlargement of the thyroid gland has been recorded as "slight" when the enlargement could be distinctly felt but was not always sufficient to attract the patient's attention, as "moderate" when it was easily seen and felt, and as "considerable" when it was very obvious and disfiguring. In 27 cases the enlargement was sljght, in 36 it was moderate, and in 20 it was considerable. In one, in which the goitre had been present for 34 years, it was enormous, the circumference of the neck being 23 inches. In 28 cases the size was not defined in the notes, and in eight there was no enlargement at the time of the examination, though, as already stated, in five of these there had been a previous enlargement.

In 89 cases there is a note as to the character of the enlargement of the gland. This was generally uniform, the right lobe often being larger than the left, as it is in the normal glard. In only two cases was the left lobe larger than the right. In two cases the right lobe alone was enlarged, and in one the right lobe and the isthmus. In four cases an adenoma or cystic adenoma of the isthmus was associated with general enlargement of both lobes. In one case the left lobe only was enlarger and also contained a small adenoma or cyst. In one case there was an adenoma in the right lobe and in another in the left lobe. In one case there was an enormous fibro-cystic goitre of long duration. A thrill over the enlarged gland was felt in only 14 cases, in 30 it was noted as being absent, and in the remaining 76 no note on this point was made. In 33 cases a bruit was heard over the goitre. In 23 of these it was systolic in time. In seven there was a continuous venous murmur, which in three became much louder with each systole of the heart. In one other case a venous murmur was heard outside the lateral lobes at the base of the neck. In 17 cases it was noted that no murmur was present, and in the remaining 68 cases this point was not noted.

Circulatory system. -The frequency of the pulse was distinctly increased in all the cases. In those which were seen on two or more occasions it was found to vary considerably, and in these I have taken the greatest observed frequency in each case. The frequency was recorded in 118 cases; in the other two it was increased, but the actual pulse-rate was not recorded (Table II.).

TABLE II.-Showing the Frequency of the Pulse.

\begin{tabular}{|c|c|c|c|c|}
\hline Pulse & e frequency. & $\begin{array}{l}\text { Number } \\
\text { of eases. }\end{array}$ & Pulse frequency, & $\begin{array}{l}\text { Number } \\
\text { of cases. }\end{array}$ \\
\hline Between & 90 and $100 \ldots$ & 3 & Between 160 and $170 \ldots$ & 11 \\
\hline , & $100,, 110 \ldots$ & 8 & $170,180 \ldots$ & 1 \\
\hline ,. & $110,, 120 \ldots$ & 8 & $180,190 \ldots$ & 5 \\
\hline$"$ & $120,, 130 \ldots$ & 20 & $190,200 \ldots$ & 0 \\
\hline , & $130,, 140 .$. & 15 & At $200 \ldots \ldots$ & 5 \\
\hline ,, & $140,, 150$. & 31 & & - \\
\hline, & $150,, 160$ & 11 & & 318 \\
\hline
\end{tabular}

The frequency of the pulse thus varied from $90 \mathrm{up}$ to 200. In no less than 66, or more than half the cases, the pulse was between 120 and 150 . In 31 of these, or more than one quarter of the cases, it was between 140 and 150 . The high frequency of 200 was counted generally during a temporary attack of palpitation and was not persistent. Great variation was sometimes observed in the same case within a short time. Thus in one case the pulse-rate fell in a few minutes from 180 to 140 ; an ice-bag was then applied to the præcordium and in a quarter of an hour the pulse bac fallen to 112 . 
The pulse was usually regular, small, and compressible. Irregularity of rhythm was observed in only eight of the cases, and in one other the pulse was irregular in force but not in time.

Heart. - Murmurs occurred rather frequently. A systolic murmur, heard most distinctly in the second left intercostal space close to the edge of the sternum over the pulmonary area, was present in 17 cases. In some of these cases this murmur was loud and very rough, almost purring in character. In 16 cases a systolic murmur was heard at the apex, and in eight a systolic murmur was heard at the apex and over the pulmonary area as well. In one of the cases in which a systolic murmur was heard at the apex over the mitral area the first sound was so much accentuated as to be distinctly audible when the ear was held several inches away from the chest. In one case a systolic murmur was heard over the inner end of the third left intercostal space, and in only one was a presystolic murmur heard at the apex. In 24 cases no murmur was heard at all, and in the remainder no murmur was noted. In one case there were occasional attacks of syncope, and in another attacks of vaso-motor angina.

As is usual in Graves's disease, pulsation was felt over a larger area than normal in the region of the apex beat. Taking the lowest and outermost point at which pulsation could be distinctly felt as the apex beat it was found in 19 cases to be in the fifth left intercostal space in the nipple line. In exactly the same number of cases it was outside the nipple line at distances varying from half an inch to two inches beyond it. In one case it was in the sixth space in the nipple line and in one in the sixth space one finger's breadth outside the nipple line. In two cases it was in the anterior axillary line. In eight cases the impulse was normal or internal to the left nipple line. In the remaining 70 cases no special note of the position of the apex beat was made.

Eye symptoms. - Although exophthalmic goitre is the usual name of the disease it is important to bear in mind that exophthalmos is often absent. This absence of the most noticeable symptom of all not infrequently has led to the disease being overlooked. In my series a note was made of the condition of the eyes in 114 cases. In 79 cases there was exophthalmos; in three there had been prominence of the eyeballs at an earlier stage which had subsided before I saw them. In no less than 32 cases, or more than one quarter, there was no exophthalmos at all. Von Graefe's symptom, a delay in the natural fall of the upper eyelids when the eyes are directed downwards, was present in 36 out of 91 cases in which the presence or absence of this symptom was specially noted. Retraction of the upper eyelids, commonly known as Stellwag's sign, was observed in 47 cases, in 29 it was absent, and in the remaining 44 no mention of it was made in the notes.

On examining how these symptoms were combined I find that in 33 cases the exophthalmos was present alone, in nine retraction of the upper lids with widening of the palpebral fissure as a consequence occurred alone, while von Graefe's symptom was present alone in only one case. All three symptoms were present together in 27 cases, in eight exophthalmos and von Graefe's symptom occurred together with. out Stellwag's sign, and in 11 exophthalmos and Stellwag's sign without von Graefe's symptom.

Nervous system. - A fine regular tremor of the hands, which is best seen when the arms and hands are extended in front of the patient, is one of the most constant symptoms in exophthalmic goitre. This statement receives strong support from my cases. In 111 cases this tremor was present. In some of these it was very well marked, in others slight, and in some it was not observed on every occasion. In six of these cases it was noted as being present in the feet as well as in the hands. Probably it was present in the feet in other cases as well, as this was not looked for in all. The tremor was generally quite regular in rhythm, in one case it was rather irregular, and in five cases, in addition to the ordinary fine tremor of the extended hand, there were irregular jerky movements of larger amplitude. In four cases no tremor at all was found and in five there is no note on this point.

A peculiar mental condition of nervousness is a common symptom in exophthalmic goitre. Such patients are generally in a state of suppressed excitement, similar to that of a man just before a boat-race or on the eve of an examination. In 70 of my cases this condition was present, in three cases it was absent, and in the remaining 47 no special note was made as to the mental state. In some cases the patient's temper was irritable. Some were very emotional and easily perturbed by trifling events, such as would not upset the equanimity in health. Thus one patient stated that she became alarmed when her husband was late in returning from his work, and when assisting at a confinement was more nervous than the patient herself. In some cases restlessness was a marked feature; this was specially so in one of the men who, while talking, was continuously changing his position, crossing and uncrossing his legs, and placing first one arm and then the other over the back of his chair. He, like some of the other cases, was remarkably insensitive to cold and in the depth of winter felt quite warm while wearing the lightest of summer clothing and no overcoat out of doors.

One male patient had melancholia with suicidal tendencies and used to cry for several hours at a stretch, and in another case there had been suicidal tendencies for three months following the last confinement. No evidence of insanity was observed in any of the other cases. In only two cases were definite hallucinations described. Both these patients were perfectly sane. One on waking saw figures standing by her bed; she had also seen a cat on the bed and had heard a bell ringing. 'The other used to see figures at the foot of her bed at night, the faces being those of people who were dead, which appeared just as she last saw them. This symptom was not systematically inquired for and may have been present in other cases as well, for Dr. Henry Head has pointed out that patients seldom complain of hallucinations unless specially asked about them in favourable circumstances. One patient complained of nightmare. Insomnia was present in four cases. One of these patients stated that she could not sleep for nervousness and another used to lie awake till 4 or 5 A.M. Headache was complained of in five cases and was usually of a migrainous type. In one other case there were attacks of migraine, during which the goitre was enlarged and the eyes became more prominent. Sudden attacks, in which many of the symptoms became greatly intensified for a few hours, occurred in some cases. In one such attack, during which I saw the patient, she complained of feeling "numb" all over. The face became flushed and there was profuse general perspiration. The temperature was $101^{\circ} \mathrm{F}$ and the pulse was 200 . There were general muscular tremors. After an ice-bag was applied to the præcordium the pulse fell to 156 . The attack lasted about four hours. Weakness of the legs was complained of by 15 patients. Five of them stated that the legs felt weak, as if they would give way while walking. Seven complained that the legs actually gave way and five of these fell or were unable to walk at the time in consequence of this sudden loss of power. One patient who fell when she was out walking was unable to rise again without assistance. Various other nervous symptoms were observed in single cases which are not sufficiently important to mention in detail.

Skin. - The skin generally feels warm and may be flushed at times. It is very frequently moist from an increase of insensible perspiration or from actual sweating. In some cases the skin is nearly always moist and at times there are profuse sweats as well. In 76 of my cases there was unusual dampness of the skin and in 55 of these there was sweating. More or less pigmentation of the skin was observed in 22, or rather more than one-sixth of the cases. The brown pig. mentation was most marked on the exposed portions of the skin of the face, neck, and hands. In several cases it was especially marked on the eyelids and around or beneath the eyes. In one the outer edges of the areolæ and the front of the leg showed the pigmentation most markedly. In one case there was general diffuse pigmentation of the face, the neck, the forearms, and the hands, with darker freckle-like patches on the backs of the hands and forearms. In one case the patient used formerly to suffer greatly from chilblains which disappeared when she developed exophthalmic goitre. As she improved, however, the chilblains began to return. Loss of hair was noted in ten cases. This generally occurred in the earlier or more acute stages of the disease. The hair generally grew again as the other symptoms subsided. In two of these cases the scalp became almost entirely bald, and in one this was accompanied by loss of eyebrows and eyelashes as $w \in 11$.

Respiratory system. - Increased frequency of respiration was observed in some cases but did not as a rule give rise to any discomfort. In one case which I saw with Dr. A. W. Messer of Lemington rapid respiration was the first symptom which attracted attention, and as it appeared just after an 
attack of influenza it suggested the onset of an attack of pneumonia. The respiration was 40 and the pulse was 75 . Later when I saw the case the respiration was 36 and the pulse was 150. By that time the ordinary symptoms of exophthalmic goitre had developed. I may add that in this case the disease ran a short acute course, with uncontrollable vomiting, and terminated fatally. Two of the patients suffered from phthisis and in another there had been some hæmoptysis, but there were no physical signs of pulmonary disease. In two cases there was expectoration of a large amount of watery mucus ; in one of them about ten ounces
of frothy clear mucus were expectorated each day for a week.

Digestive system. - Variations in the appetite were noticed in 11 cases ; in four of these it was diminished and in seven it was increased or there was actual craving for food. An
increase in the appetite, when present, usually occurred in the early stages of the disease. Thirst was complained of in four cases. Vomiting occurred in seven cases; in two of these it was severe and continued and largely contributed to the fatal issue. The most frequent symptom was diarrhœa. This usually occurred in the form of short attacks of painless diarrhœe of one or several days' duration. These attacks often started suddenly and terminated in the same manner. This liability to diarrhcea was noted in 35 cases, or rather more than one-fourth of the total number. Constipation was present in eight cases. In four cases there was increased frequency of defecation. This symptom must be distinguished from diarrhoea, as it may be mistaken for it by the patient. The bowels act twice or thrice each day, but the motions are quite normal in character.

Urine. The condition of the urine was, unfortunately, only noted in 19 cases. In four of these a trace of albumin was found and sugar was found in three; in one of these there were 15 grains to the ounce of urine and in another there were 40 grains.

Generative system. - In the 110 cases in women some irregularity in menstruation was noted in 23 cases. Amenorrhoea for periods of varying lengths, from five months to eight years, was present in ten cases. In several of these menstruation ceased for a time during the earlier and more acute stages of the disease, and returned again as improvement in the other symptoms took place. In four cases the loss was scanty, in two it was irregular, and in three it was both scanty and irregular. In two cases the menstrual loss was excessive, but in one of these this was accounted for by the presence of retroflexion and retroversion of the uterus. In two cases menstruation occurred too frequently and the loss was excessive as well.

Nutrition.-Wasting is a common symptom and in some cases the loss of weight may amount to several stones. Some loss of flesh was noted in 45 of my cases. The loss of weight was usually greatest when other symptoms were fully developed and a regain of weight was one of the indications of general improvement. Thus one case at the height of the disease weighed only 6 stones and when seen again, eight years later, she had gained 3 stones 11 pounds, while the other symptoms had subsided. The male patient, who was seen in June, 1899, with simple parenchymatous goitre, and again in November, 1901, with fully developed exophthalmic goitre, had lost from two and a half to three stones in the interval.

Cour'se.-The course of exophthalmic goitre is generally slow and protracted and runs so differently in different cases that it is difficolt to follow and prognosis is often uncertain. As examples of the disease running a short course I may mention two of my cases-one favourable and the other the reverse. In one case, that of a single woman, aged 29 years, the symptoms first commenced in December, 1900, and were well marked in February, 1901, when the pulse was 144. After this she rapidly improved, so that by the following September the pulse had fallen to 72 and she was practically well and able to undertake the work of a sister in a children's hospital, the whole attack having lasted only nine months. In the other case, that of a married woman, aged 52 years, the symptoms had all developed after an attack of influenza 11 weeks before I saw her and were well marked and severe. She had uncontrollable vomiting, to which she succumbed shortly afterwards. In most of the cases, however, the disease ran a much more chronic course, extending to several years. In one case little or no change took place in the patient's condition during six years. As a rule, however, there was a first period of gradual development of the symptoms extending over many weeks or even months; this
was followed by another period, during which the symptoms were more or less stationary, lasting for several months or even years, after which, in a favourable case, the symptoms gradually improved.

Even in the most favourable cases a patient after an attack of exophthalmic goitre seldom returns quite to the normal condition she was in before in the way a patient recovers, for example, from an attack of enteric fever. In a considerable number there is a practical recovery, so that the patient feels well and complains of nothing, but a careful examination often shows that the pulse is still unduly frequent and excitable, or the thyroid gland remains slightly enlarged, or there is rather a staring expression or some general nervousness. Thus in one of my cases there had evidently been well-marked exophthalmic goitre, commencing 20 years before I saw her, and from which she considered she had recovered. The pulse was 92 , the eyes were slightly prominent, and there was retraction of the upper eyelids, but the thyroid gland had returned to its normal size. Out of 40 of my cases in which the patient was seen from time to time, or information obtained as to the course of the disease, death occurred in seven, two remained stationary, and 31 progressed favourably. Of these 31 in which improvement took place, nine patients practically recovered, though two of them afterwards had partial relapses, eight were greatly improved, and $14 \mathrm{im}-$ proved to a certain extent. In none of my cases was ex. ophthalmic goitre followed by myxodema. I have only had the opportunity of examining one case in which this interesting sequence occurred, that of a patient shown by Dr. $G$. Scott Jackson of Alnwick at a meeting of the North of England Branch of the British Medical Association.

\section{TREATMENT.}

The treatment of exophthalmic goitre is a large question and the time at my disposal will not permit of a detailed account of the treatment adopted in all my cases. I shall therefore confine myself to a short account of the lines of treatment which have proved to be most successful.

No hard-and-fast lines can be laid down for the treatment of this disease. The symptoms vary so much in different cases that in each one the treatment has to be adapted to the special symptoms present and the social position of the patient. In the first place comes the general bygienic treatment of the patient. If the symptoms are severe absolute rest in bed for three or four weeks is essential. In cases in which the nervous symptoms are predominant, or when there has been rapid emaciation, rest in bed may be combined with isolation, liberal feeding (especially with milk), massage, and electricity ; in other words, a course of what is known as "Weir-Mitchell treatment" is of great service. In less severe cases and in cases in which rest in bed has already been carried out it is well to regulate the patient's mode of life as far as circumstances permit of it. At least 12 hours should be spent in bed, from $10 \mathrm{P}$. M. to $10 \mathrm{~A} . \mathrm{M}$., breakfast being taken in bed. In addition to this in many cases the patient should lie down from 2 to 3 P.M. and from 6 to 7 P.M. A quiet life in the country or at the seaside, as free as possible from excitement or effort, is most suitable. As much time as possible should be spent in the open air, partly reclining on a deck-chair and partly in taking gentle walking exercise, which may be gradually increased from half a mile up to three or four miles a day, according to the progress made. As sufferers from exophthalmic goitre do not feel the cold easily and are not liable to catch cold they can spend much time out of doors nearly all the year round.

Electricity is most useful in many cases, but is not sufficiently employed, owing to the modes of application recommended being too elaborate. The faradic current may be employed easily and efficiently by a method which was first described to me by Sir Victor Horsley. Two flexible metal electrodes, about four inches long and two inches wide, covered with wash-leather which are connected by a small strap and buckle on each side, are moistened and accurately applied to the neck. One electrode is placed in front over the thyroid gland and the other over the back of the neck; the straps are then tightened so as to keep them in pcsition. The electrodes are connected with the secondary coil of a small dry-cell faradic battery, and sufficient current is turned on to produce a distinct prickling sensation. The faradic current should be applied in this way for an hour each night and morning for several months. Not only do patients feel relieved for a time by each application of the $A$ A 2 
current in this manner but I have seen steady improvement take place under its continued use.

In many cases no special diet is necessary. When there is any emaciation a liberal diet is required which may be supplemented by two extra pints of milk in the day. If there is great emaciation forced feeding may be necessary.

In a large number of cases, and especially in those which are seen in hospital out-patient practice, we can unfortunately carry out little more than medicinal treatment and often in circumstances which are not at all favourable to recovery. Belladonna was frequently prescribed and was useful in some cases but I have often been disappointed in the results of its use. To be of service in exophthalmic goitre any line of treatment should be steadily maintained for some weeks or even months and patients of ten dislike to continue taking bellatonna in sufficient doses to produce physiological effects. Convallaria has proved useful in cases in which the frequency of the pulse has been very high and is more effectual in lowering the pulse-rate than other cardiac tonics. Bromides are useful in cases in which there are marked nervousness and tremors. Arsenic is uceful in nearly all cases and may be combined with other drugs with advantage. The best results are obtained by giving small doses of three or four minims of Fowler's solution three times a day for a month or two or for the first three weeks of each month for five or six months. Of the animal extracts thymus and suprarenal tablets have both been of service. Thyroid extract is harmful, as it often exaggerates the symptoms, and should not be given in exophthalmic goitre. Special measures are frequently required for the treatment of urgent symptoms. The sudden attacks of diarrhoea were readily controlled by laudanum and dilute sulphuric acid. Severe attacks of palpitation with very rapid pulse yielded to the application of an ice-bag to the præcordial area. Persistent vomiting in acute cases is difficult to treat. On the whole rectal feeding and the administration of morphia, either subcutaneously or by the rectum, gave better results than other lines of treatment.

Newcastle-on-Tyne.

\section{THE INCIDENCE OF ALKAPTONURIA : A STUDY IN CHEMICAL INDI- VIDUALITY.}

BY ARCHIBALD F. GARROD, M.A., M.D. OxOx., F.R.C.P. LOND.

PHYSICIAN TO THE HOSPITAL FOR SICK CHILDREN, GREAT ORMONDSTREET; DENONSTRATOR OF CHEMICAL PATHOLOGY AT ST. BAR'THOLOMEW'S HOSPITAL.

ALI the more recent work on alkaptonuria has tended to show that the constant feature of that condition is the excretion of homogentisic acid, to the presence of which substance the special properties of alkapton urine, the darkening with alkalies and on exposure to air, the power of staining fabrics deeply, and that of reducing metallic salts, are alike due. In every case which has been fully investigated since Wolkow and Baumann ${ }^{2}$ first isolated and described this acid its presence has been demonstrated and re-examination of the material from some of the earlier cases also has led to its detection. The second allied alkapton acid, uroleucic, has hitherto only been found in the cases investigated by Kirk and in them in association with larger amounts of homogentisic acid. ${ }^{2}$ By the kindness of Dr. R. Kirk I have recently been enabled to examine fresh specimens of the urines of his patients who have now reached manhood and was able to satisfy myself that at the present time even they are no longer excreting uroleucic acid. After as much of the homogentisic acid as possible had been allowed to separate ont as the lead salt the small residue of alkupton acid was converted into the ethyl ester by a method recently described by Erich Meyer ${ }^{3}$ and the crystalline product

1 Wolkow and Baumann : Zeitschrift für physiologische Chemie, 1891, Band Xv., p. 228.

2 R. Kirk : Journal of Anatomy and Physiology, 1889, vol. xxiii. p. 69. Huppert: Zeitschrift fur Physiologische Chemie, 1897, Band xxili., p. 412 . p. 443 , obtained had the melting-point of ethyl homogentisate $\left(120^{\circ} \mathrm{C}.\right)$. Further observations, and especially those of Mittelbach, ${ }^{*}$ have also strengthened the belief that the homogentisic acid excreted is derived from tyrosin, but wh alkaptonuric individuals pass the benzene ring of their tyrosin unbroken and how and where the peculiar chemical change from tyrosin to homogentisic acid is brought about, remain unsolved problems.

There are good reasons for thinking that alkaptonuria is not the manifestation of a disease but is rather of the nature of an alternative course of metabolism, harmless and usually congenital and lifelong. Witness is borne to its harmlessness by those who have manifested the peculiarity without any apparent detriment to bealth from infancy on into adult and even advanced life, as also by the observations of Erich Meyer who has shown that in the quantities ordinarily excreted by such persons homogentisic acid neither acts as an aromatic poison nor causes acid intoxication, for it is not excreted as an aromatic sulphate as aromatic poisons are, nor is its presence in the urine attended by any excessive output of ammonia. However, regarded as an alternative course of metabolism the alkaptonuric must be looked upon as somewhat inferior to the ordinary plan, inasmuch as the excretion of homogentisic acid in place of the ordinary end products involves a certain slight waste of potential energy. In this connexion it is also interesting to note that, as far as our knowledge goes, an individual is either frankly alkaptonuric or conforms to the normal type, that is to say, excretes several grammes of homogentisic acid per diem or none at all. Its appearance in traces, or in gradually increasing or diminishing quantities, has never yet been observed, even in the few recorded temporary or intermittent cases. In cases in which estimations have been carried out the daily output has been found to lie within limits which, consilering the great influence of proteid food upon the excretion of homogentisic acid and allowing for differences of sex and age, may be described as narrow. This is well illustrated by Table [., in which the cases are arranged in order of age :-

TABLE 1. - Shurving the Average Excretion of Homogentisic Acid.

\begin{tabular}{|c|c|c|c|c|c|c|}
\hline No. & Sex. & \multicolumn{2}{|r|}{ Aggr. } & \multicolumn{2}{|c|}{$\begin{array}{c}\text { Average excretion } \\
\text { of homogentisic } \\
\text { acid per } 24 \text { hours on } \\
\text { orlinary mixed } \\
\text { diet. }\end{array}$} & Names of obser vers. \\
\hline 1 & M. & & years. & $3 \cdot 2 y$ & ammes. & Eı ich Meyer. \\
\hline 2 & M. & $3 \frac{1}{2}$ & , & $2 \cdot 6$ & , & A. If Garrod. \\
\hline 3 & M. & 8 & , & $2 \cdot 7$ & , & Ewald Stier. \\
\hline 4 & M. & 18 & , & $5 \cdot 9$ & , & P. Stango. \\
\hline 5 & M. & 44 & $"$ & $4 \cdot 6$ & , & Mittelbach. \\
\hline 6 & $\mathbf{M}$ & 45 & , , & 47 & , & II. Ogden. \\
\hline 7 & $\mathbf{M}$ & 60 & , & $5 \cdot 3$ & , & Ilammarstell. \\
\hline 8 & F. & 60 & , & $3 \cdot 2$ & ,. & It Emblen. \\
\hline 9 & M. & 68 & , & $4 \cdot 8$ & ", & Wulkow and Baumann. \\
\hline
\end{tabular}

The information available as to the incidence of alkapton uria is of great interest in connexion with the above view of its nature. That the peculiarity is in the great majority of instances congenital cannot be doubted. The staining property of the urine allows of its being readily traced back to early infancy. This has been repeatedly done and in one of my cases ${ }^{5}$ the staining of the napkins wa; conspicuous 57 hours after the bis th of the child. The abnormality is apt to make its appearance in two or more brothers and sisters whose parents are normal and among whose forefat hers there is no record of its having occurred, a peculiar mode of incidence which is well known in connexion with scme other condition:. Thus of 32 known examples, which were presumably congenital, no less than 19 have occurred in seven families. One family contained four alkaptonurics, three others contained three, and the remaining three two each. The proportion of alkaptonuric to normal members is of some interest and Table II. embodies such definite knowledge upon this point as is at present available regarding congenital cases.

4 Mittelbach : Ibid, 1901. Band lxxi., p. 50

A. E. Garrod : THe LaYCEr, Nov. 30th, 1901 . p. 1487; Transactions of the Royal Medical and Chirurgieal Society, 1902, yol. Ixxxr., p. 69 , 